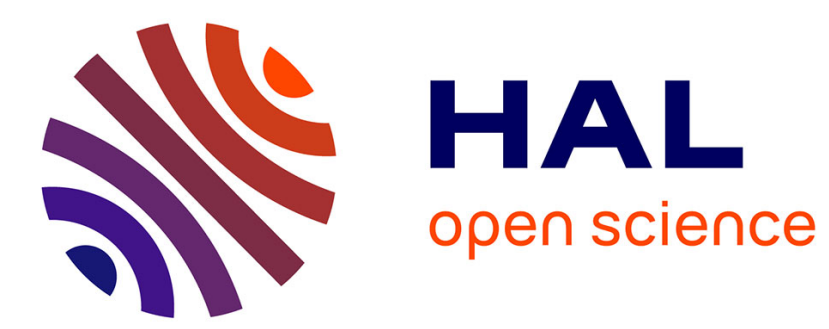

\title{
COPING WITH THE TRAGEDY OF THE COMMONS: GAME STRUCTURE AND DESIGN OF RULES
}

Nicolas Faysse

\section{- To cite this version:}

Nicolas Faysse. COPING WITH THE TRAGEDY OF THE COMMONS: GAME STRUCTURE AND DESIGN OF RULES. Journal of Economic Surveys, 2005, pp.239-261. cirad-01002167

\section{HAL Id: cirad-01002167 http://hal.cirad.fr/cirad-01002167}

Submitted on 5 Jun 2014

HAL is a multi-disciplinary open access archive for the deposit and dissemination of scientific research documents, whether they are published or not. The documents may come from teaching and research institutions in France or abroad, or from public or private research centers.
L'archive ouverte pluridisciplinaire HAL, est destinée au dépôt et à la diffusion de documents scientifiques de niveau recherche, publiés ou non, émanant des établissements d'enseignement et de recherche français ou étrangers, des laboratoires publics ou privés. 


\title{
COPING WITH THE TRAGEDY OF THE COMMONS: GAME STRUCTURE AND DESIGN OF RULES
}

Nicolas Faysse, UMR G-Eau, Cirad

This is the post-refereeing version of the article with the same title, which has been published in final form in the Journal of Economic Surveys, 2005,19(2): 239-261, at http://onlinelibrary.wiley.com/doi/10.1111/i.0950-0804.2005.00246.x/abstract

\begin{abstract}
The paper provides an assessment of some recent results of the large amount of New Institutional Economics analyses investigating a common-pool resource setting, with a specific focus on game theory models. Most of the studies have used a non-cooperative approach in order to explain how under-provision for the resource or its over-use - the so-called Tragedy of the Commons - can be avoided, within given management rules. They show how the characteristics of the game (payoff matrix, repetition) or of the users (group size, wealth, heterogeneity and moral norms) may give incentives for the latter to play in a way that benefits all users. By contrast, much fewer articles have used a formalized approach to assess the possibility for players to design new rules to overcome the initial Tragedy of the Commons. The article ends with some proposals of directions for future research.
\end{abstract}

Keywords. Common-pool resource; Heterogeneity; Non-cooperative game theory; Prisoners' Dilemma; Tragedy of the Commons

\section{Introduction}

Hardin's famous article 'The Tragedy of the Commons' in 1968 brought to the fore the problems of management of the resources held in commons: forestry, water, fishery, pastures, etc. The core idea of the paper was that in any situation where a resource is held in common among a group of users, every user has the incentive to exploit the resource at a level that is collectively inefficient. In the example given by Hardin, once social stability and the absence of diseases do not limit the size of the herds, shepherds' freedom to decide how many animals they send to a common village pasture leads necessarily to a situation of overgrazing. The issue raised by Hardin has become of increasing importance. This is because, in both developing and developed countries, heated debates have often taken place on whether commons should be in the hands of user groups, nationalized or managed through a system of private property rights. Currently, none of these property regimes appear to provide a blanket solution for all situations (Stern et al., 2002). In the last three decades, a growing number of scholars have started focusing on this issue, drawing from many disciplines: anthropology, economics, psychology, political science, etc. (Hardin, 1998; see also a brief history of research on the commons in Dietz et al., 2002). The underlying assumption of most of this research has been that 
the misuse of the commons is not a necessary outcome. More specifically, this subject has become one of the most important fields of investigation of the 'Collective Action Theory', a branch of the New Institutional Economics (Kherallah and Kirsten, 2002).

This review aims at assessing the recent results of this approach in analyzing the problem of the commons, with a specific focus on the use of game theory models. More precisely, the systems studied here are common-pool resources (CPR), defined by Ostrom et al. (1999) as 'natural (or) human-constructed resource systems in which (i) exclusion of beneficiaries through physical and institutional means is especially costly, and (ii) exploitation by one user reduces resource availability for others'. This definition does not refer to any property rights. Actually, four types of property rights can be associated with such a resource: open access, group property, individual property or government property.

The fundamental problem for a CPR, called the free rider or ' $1 / n^{\prime}$ ' problem, appears in situation of unmanaged commons, defined as a situation where no rule monitors the access to the resource and the actions undertaken by agents. This problem can be divided into two dilemmas: the underprovision of the collective good and the over-investment for the use of the resource (Ostrom et al., 1994). Regarding the provision of the resource, agents must invest to create or maintain either the resource, which will be collectively available, or the means to use it (e.g. an irrigation scheme). In such a situation, each agent bares the full costs of providing for the collective good, while he enjoys only a fraction of the benefits of his action, because all agents afterwards use the collective good. Without a rule to monitor the investments, the total amount invested will be less than the optimum from the collective point of view and will not achieve a Pareto optimum. This problem is not specific to CPRs, because it occurs also for all public goods. Regarding the issue of appropriation, agents make individual efforts or investments, in order to use the resource. Moreover, each agent's effort to exploit the resource will reduce resource availability for all users. In this case, each agent profits completely from his effort while he bares only a share of the negative consequences of his exploitation of the collective good (the decrease of the available resource). Without a rule to monitor the use of the resource, there will be an excessive collective effort for the appropriation of the CPR, which will lead to a low rate of return for the initial investment (and sometimes a risk of destruction of the resource itself). Such a result will also not be Pareto-optimal.

It is important to note that the definition of a CPR, proposed by Ostrom et al. (1999), encompasses the pollution problems only in so far as the polluters are also affected by their own pollution activities (for instance mines that would need to pump clean water from a lake but that would send their industrial effluents in the same lake). Besides this, the difference between the CPR appropriation problem and the one of congestion of a public good is that in the second case, agents do not need to make an effort to benefit from the resource.

Free riding can take place in an unmanaged CPR, whatever the property regime actually in place. For instance, a group property regime might indeed delimitate clearly the entitled users from the nonauthorized users outside the group, but the rules in place may fail to control the provision or extraction of the resource. In contrast, in a managed CPR, some rules define what users are either required to provide for the resource or entitled to withdraw from it. These rules hence prevent the inefficiency stemming from the free rider problem. Such a basic distinction between managed and 
unmanaged commons is obviously of interest mainly for analytical purposes because, in practice, many rules address partially the free rider problem.

This review of literature shows that the initial objective of most of the new institutional economics analyses of CPR is met: many characteristics of the game characterizing players' interactions can be involved to show that the Tragedy of the Commons is not the necessary outcome. Nevertheless, all these studies remained in the framework set in Hardin's (1968) seminal analysis, that is, a given setting where agents can choose their actions but cannot gather to design new management rules. The economic analysis of agents' capacity to design these rules is, however, much more limited, but it can draw some results from the preceding non-cooperative analysis. On the whole, the noncooperative analysis provides a good understanding of what happens in the field when users cannot or do not want to change the rules. Otherwise, when agents are allowed to set up rules, a precise analysis must be undertaken for each case, which will take into account the structure of the initial game and of the negotiation.

The paper is organized as follows: Section 2 describes the main paradigm used to tackle the issue, where the existing rule, if any, allows agents to choose among actions that will have different positive or negative impacts at the collective level. Section 3 summarizes several studies, which focus on the characteristics of the game and of the users, and which show how, within a given set of management rules, the Tragedy of the Commons is not the necessary outcome of the game. The fourth section presents the much less abundant economic literature that deals with the design of new management rules. Section 5 provides a brief overview of the contribution of economic analysis to the debate about CPR. Finally, the last section proposes some directions for future research.

\section{The Very Restrictive Paradigm of a Given Management Rule}

Hardin (1968) considered that, because of the free rider problem, every CPR was doomed to overexploitation. The idea behind this is the prisoners' dilemma ${ }^{1}$. Hardin used the term 'tragedy' in the sense of something inescapable, which imposes its own logic to each player. Obviously, the term became famous because of its other meanings. Hardin thought that the only solutions to avoid the Tragedy of the Commons were nationalization or the definition of individual transferable rights. Actually, Hardin denied the possibility for users to design management rules and implement them. Given this assumption, group property is deemed to lead to a situation of open access ${ }^{2}$. For the last 15 years, most of articles written on CPR management positioned themselves against such a simplistic amalgamation of group property and open access.

Economists have tried to explain that the Tragedy of the Commons could be prevented (i) either by showing that some situations could be modelled by other games than the Prisoners' Dilemma (ii) or

\footnotetext{
${ }^{1}$ The prisoners' dilemma formalizes the situation where 'two conspirators are captured by the police. If neither informs on the other, they both face light sentences. If both inform, they both face long jail terms. If one informs and the other does not, the informer receives a very light sentence or is set free while the noninformer receives a heavy sentence. Faced by this set of payoffs, the narrow self-interest of each will cause both to inform, producing a result less desirable to each than if they both remained silent' (Dietz et al., 2002). Another crucial assumption is that the prisoners cannot communicate and cannot commit themselves ${ }^{2}$ Actually, Hardin (1998) acknowledged later that his 1968 analysis has to be limited to unmanaged commons.
} 
by keeping the initial structure of the Prisoners' Dilemma and by inserting it in a more global structure (for instance, games repeated for an unknown duration or existence of moral norms).

By doing this, these studies do not take into account the ability of users to set up their rules and, thus to shift from an unmanaged to a managed CPR. Hence, most of these articles remain within the initial paradigm, where agents act on their own, without any possibility to craft common management rules in a bottom-up process. Within the new institutional economics approach, this mirrors in the large use of non-cooperative games and the near absence of formalized models of negotiation.

Two main reasons might explain this focus. First, in many cases, the CPR is bound to remain unmanaged because either agents cannot set up a managed CPR or do not want to set up management rules. Agents' willingness to set up management rules will be analysed in section 4 . The possible impossibility of setting up a managed CPR refers to the proposed boundary line between cooperative and non-cooperative games as proposed by Harsanyi (1966), for whom a game is in the cooperative category if engagements made by the players cannot be revoked. Even if this definition is still problematic (Schmidt, 2001), it clarifies the paradigm used in most CPR analyses: (i) rules that would engage users irrevocably are either impossible or too costly; and (ii) users cannot create the conditions that would allow such non-revocable rules. The second reason is simply that noncooperative theory is easier to handle than the different cooperative theories and provides results that have a much better predictive power.

\section{Within an Unmanaged Situation, the Tragedy of the Commons is not a Necessary Outcome}

This section presents an assessment of different economic studies that analyse conditions enabling collective efficiency in an unmanaged CPR setting. (Hereafter, collective efficiency will stand for the outcome of agents' choices relative to the goals of either maximizing the amount of resource provided or limiting the total investment made for appropriation of the resource). Hence, all users can choose their own action and do not communicate to craft management rules. In such a situation, the interactions among players can be described as a non-cooperative game. Within this framework, the possibility to prevent a Tragedy of the Commons has been demonstrated using different levels of analysis. The review will first analyse the user group: (i) the average values of users' characteristics (for instance average wealth); (ii) the heterogeneity among users; and (iii) the size of the group. Second, it will examine the structure of the game: (iv) the game payoffs; ( $v$ ) the possible repetition of an initial game; (vi) the possible existence of behavioural norms; and (vii) interdependencies between the appropriation problem and the provision problem.

The following presentation is based on these seven items, in the above order. Apart from subsection (iv) on the game payoffs, the underlying structure of the game is one similar to the Prisoners' Dilemma. In the common Prisoners' Dilemma setting, agents use dominant strategies and their choices will be either good or bad for the community, whatever the choices of the other players. Hence, in a Prisoners' Dilemma setting, these choices will be hereafter called either 'collectively efficient' or 'collectively inefficient' choices. This term is preferred to the term 'cooperation', which relates to a coordination among players that does not take place in the studied non-cooperative 
setting. Similarly, 'collective efficiency' (of individually made choices) is used here rather than the term 'collective action'.

\subsection{The Impact of Users' Average Characteristics}

Both theoretical models and experimental results show that the users' average wealth can be a facilitating as much as a limiting factor for collective efficiency (Cardenas, 2003). Nevertheless, the impact of a change in the group's social cohesion on collective welfare can often be determined. For instance, during simulations of experimental economics made by Cardenas (2003) with Colombian farmers, the poor farmers are the more able to depart from the Nash equilibrium of overinvestment. Indeed, these farmers are used to dealing with CPR situations, while rich farmers, owners of their own fields, often do not have to address problems of a Tragedy of the Commons pattern.

\subsection{The Impact of Heterogeneity}

The impact of heterogeneity ${ }^{3}$ on the CPR dilemma is studied here by examining the impact of an increase in heterogeneity among users on collective efficiency, given an initial situation and especially given some management rules (or absence of them). (The impact of heterogeneity on users' ability to change the rules will be studied in section 5). Because heterogeneity can be multidimensional, it is necessary to carefully untangle the different types of heterogeneity and their impacts on agents' behaviours. The impact of heterogeneity among the group of users has been analysed with a look at four types of agents' characteristics: (i) the social position and the kind of interest for the resource; (ii) the ability to make an effort; the parameter of heterogeneity being, for example the area put under crops or the size of the fishing boat; (iii) the ability to profit from the resource; the parameter of heterogeneity being, for instance, the fishing technology used; and (iv) the availability of exit options. Baland and Platteau (1996) propose a typology of 'heterogeneity of endowments' and 'heterogeneity of interests', but the link between the latter and collective efficiency is less apparent and these categories are not mutually exclusive (Bardhan and DaytonJohnson, 2002).

Concerning the first type of heterogeneity, the experimental economics simulations made by Cardenas (2003) show that, when users' interests for a CPR are of the same nature, users' 'social heterogeneity' lessens their capacity to make collectively efficient choices. Regarding the two other sources of heterogeneity, Olson (1965) proposed the initial and pioneering idea, which specified that an increase in heterogeneity will entail that the richer users or the more able ones will have a greater share of the marginal collective profit. Hence, these richer users will be more eager to choose collectively efficient actions, and overall collective efficiency will be improved. Different analyses carried out afterwards show that the impacts of an increase in heterogeneity are not so clear-cut, both theoretically and in the field.

Heterogeneity has actually a double effect on the free rider problem (Baland and Platteau, 1999). On the one hand, as Olson argues, an increase in heterogeneity will make rich users internalize more the consequences of their actions and, hence, they will provide more for the collective good (or invest less to use it). On the other hand, this increase will diminish the (already small) propensity of poor

\footnotetext{
${ }^{3}$ I prefer to use the term heterogeneity rather than inequality, the latter referring to normative criteria.
} 
users to take into account the impact on the resource that they may cause. Because of these combined effects, it is possible to infer the following proposition: The parameter for which heterogeneity is considered (for instance landholding or initial wealth) is defined here in a generic way. First, if agents' payoffs grow in a convex way (respectively concave) with the parameter of heterogeneity, then an increase in heterogeneity will lead to an enhanced (respectively decreased) collective efficiency. Second, if there is a linear relationship between payoffs and the parameter of heterogeneity, then the overall outcome will be ambiguous and will have to be studied on a case-bycase basis.

Figure 1 gives a schematic description of four possible relations between the parameter of heterogeneity and the individual payoffs. These relations are convex, concave, linear, a situation where the relationship is concave at low values of the heterogeneity parameter, and then convex for the high values of this parameter. The 'heterogeneity function' will be defined here as the relationship between the individual payoff and the parameter of heterogeneity. Figure 1 shows the impact of an increase in heterogeneity on collective efficiency, depending on the curvature of the heterogeneity function, as hypothesized by the preceding proposition.

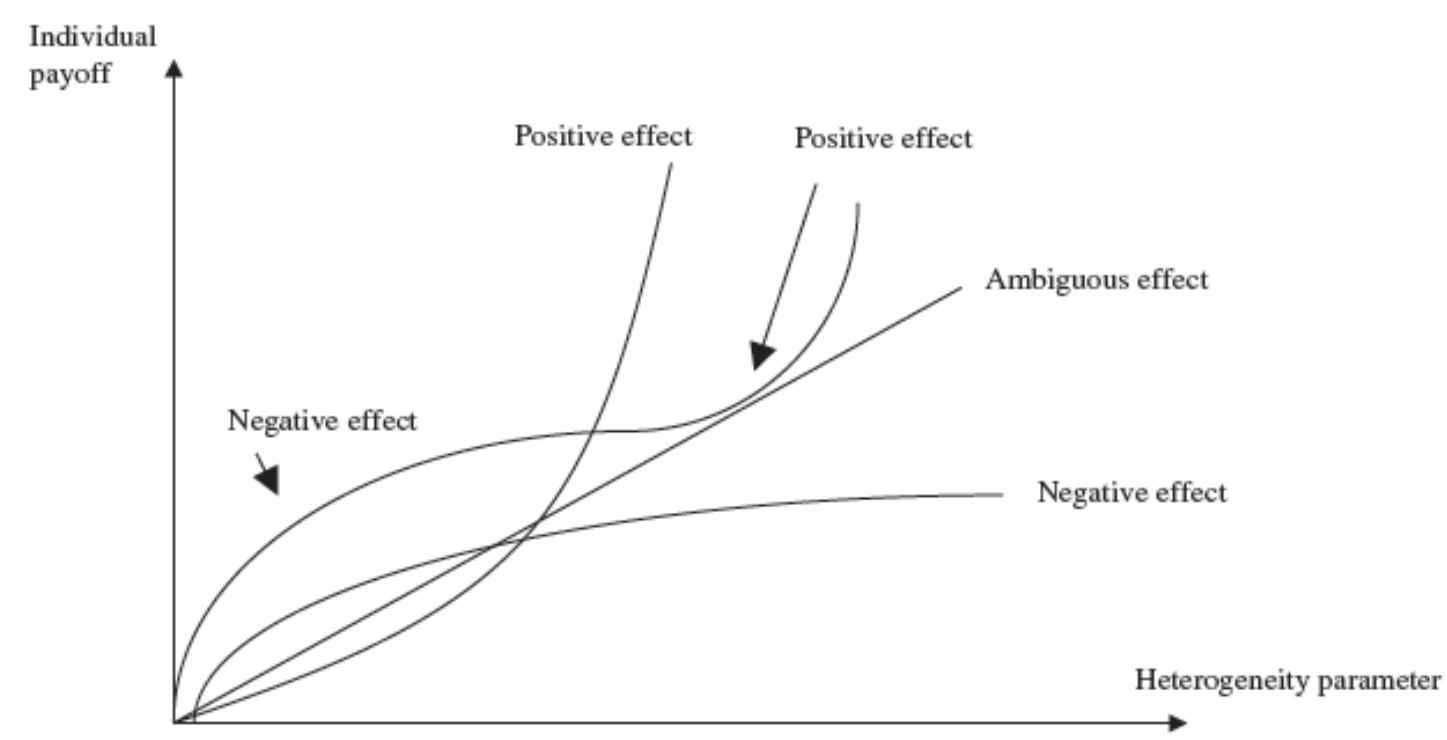

Figure 1. The impact of an increase in heterogeneity on collective efficiency, depending on the curvature of the heterogeneity function.

Many authors propose simple non-cooperative models to explore the impact of heterogeneity on the efficiency of the management of a CPR (for instance, Baland and Platteau, 1997, 1998, 1999; Bardhan and Dayton-Johnson, 2002; Dayton- Johnson and Bardhan, 2002). These articles validate the preceding proposition, within their own model settings and in a more or less explicit way. However, there is currently no model of CPR provision or use that would sustain the previous proposition in a generic fashion. Figure 2 presents a simple classification of some models dealing with heterogeneity, according to the shape of the curvature of the heterogeneity function and using the same variables as Figure 1. Figure 2 also indicates the parameter of heterogeneity used in each model.

In some cases, the structure of the game may entail a division among the group of users between a group of richer users who accept to provide for the good (or to restrain their appropriation) and a 
group of poorer users who do not and thus free ride. In these cases, the previous proposition linking the curvature of the heterogeneity function and collective efficiency does not hold. In these situations, transfer of wealth from non-contributors to contributors will lead to a better provision of the CPR (Baland and Platteau, 1997, 2002).

If the previous proposition is taken as a starting point, the question then becomes: In which cases is the heterogeneity function concave, linear, convex or with an inflexion point? The existing set of very different approaches on the subject could constitute the basis for a typology of the different possible heterogeneity functions, which would depend on the source of heterogeneity and the context of the CPR.

These different models dealing with heterogeneity also present some other results and interesting ideas that are summarized hereafter. The different types of heterogeneity will be reviewed in the following order: (i) agents' ability to make an effort; (ii) agents' ability to profit from the use of the resource; and (iii) agents' capacity to access exit options.

\subsubsection{Heterogeneity on the Ability to Make an Effort}

The capacity to make an effort is often studied from the point of view of the ability to invest at the beginning, whereby some agents are more constrained than others regarding this initial investment. An increase in heterogeneity, regarding the ability to make an effort, often does not lead to a greater marginal outcome for the more able agents; hence, the impact of such type of heterogeneity is expected to be ambiguous. Baland and Platteau illustrate such a result, with different settings, both for a provision problem (1997) and for an appropriation problem (1999). In the latter article, they take the example of a community of fishers who share a fishing zone. Fishers can choose the number of boats they will buy. An increase in heterogeneity in the ability to invest can then lead to an increase in the collective efficiency, that is, a decrease of the total number of boats at sea. Furthermore, in some cases, an increase in this heterogeneity can lead to a Pareto increase, whereby even the fishers who become more constrained in their ability to invest see their gains increased.

Dayton-Johnson and Bardhan (2002) use a simple model of fishing on a two-period basis. The Pareto optimum consists in not fishing during the first period so that the stock will be the largest possible during the second period. Collective efficiency is then a U-shaped function of heterogeneity in the capacity to invest in fishing boats, where total income decreases then increases with the degree of heterogeneity. Similarly, Bardhan et al. (2002) present a model providing a common setting for public and common goods, where each agent distributes her initial wealth between investments in a private good and in the good that is either public or CPR. The public good and the private one are complementary in agent's production function. They show that for a common good with low externality level, the total surplus (and not the total amount of collective good produced) is maximized with all agents being equal, whereas for higher externality levels, there is an optimal degree of inequality between the group of contributors and the group of non-contributors to the collective good.

Moreover, the neutrality theorem, which states that a wealth redistribution does not change the total amount of provision for a public good (Bergstrom et al., 1986) cannot be used because CPRs are not pure public goods and because a redistribution often implies a change in the number of contributors (Baland and Platteau, 1996). 


\subsubsection{Heterogeneity on the Ability to Profit from the Use of the Resource}

Agents can derive a profit (or more generally some utility) that is different from one agent to another, for the same effort made. When discount rates for the future are different, heterogeneity has an ambiguous effect on the provision of the resource (Baland and Platteau, 1997). In the same way, Baland and Platteau (1999) study the appropriation problem on the example of the choice of fishing technology. They show that heterogeneity in the number of fishing boats owned by fishers can have an ambiguous effect on collective efficiency. These findings confirm the proposition made at the beginning of this section, as the heterogeneity function is linear in these two examples.

Econometric analyses provide diverging assessments of the impact of this type of heterogeneity on collective efficiency. An econometric analysis on Mexican irrigation schemes (Dayton-Johnson, 2000b) shows that heterogeneity in landholding per household has an ambiguous effect on the total income. Another econometric study on 48 irrigation communities in India (Bardhan, 2000) demonstrates that the degree of cooperation is negatively correlated to homogeneity in landholdings, the proximity of cities and market integration, and positively correlated with the small size of the group (see also Bardhan and Dayton- Johnson, 2002 for a review of these econometric analyses).

\subsubsection{Heterogeneity in Exit Options}

Exit options are economic opportunities available to agents other than the CPR use. The DaytonJohnson and Bardhan (2002) model incorporates these exit options. The results are ambiguous but depend in part on whether the relationship between wealth and exit options is concave. Empirical evidence tends to show that exit options weaken the prospects for collective efficiency (Bardhan and Dayton-Johnson, 2002).

\subsection{The Size of the Group}

Olson (1965) made another seminal contribution by arguing that the smaller the group, the better will be the collective efficiency. Nevertheless, according to Ostrom (2000b), the size of the group has an influence on many variables (transaction costs, monitoring costs and share of every agent), and therefore, it is not possible to propose general theoretical predictions on the impact of the size of the group on collective efficiency. No optimal size appears to be pertinent in all cases (Stern et al., 2002). What matters is the social structure, especially the pre-existing authority. Wittfogel (1957) and Baland and Platteau (1996) give examples of very organized and structured societies where CPR were managed efficiently on an extended area. Farrell and Scotchmer (1988) analyse the case of a group of agents heterogeneous in their ability to invest for production but who can benefit from increasing returns to scale by gathering themselves. They show that the best users will group and then the second best users will do the same, etc. The groups set up are too small and of different compositions compared to the optimal partition. The inefficiency here stems from the ability of such groups to exclude the less able agents. This theoretical approach can explain, for instance, how fisher groups share their efforts to search for fishes.

\subsection{The Influence of the Payoff Structure}

An unmanaged CPR corresponds to a situation of moral hazard in team. Therefore, it fits within Holmstrom's (1982) model, which demonstrates that no allocation pattern exists that is a Nash 
equilibrium over agents' choices and at the same time reaches a Pareto optimum. Holmstrom also demonstrates that it is possible to approach as close as desired to the collective optimum by using group penalties. However, these penalties are obviously socially unacceptable.

More specifically, an important part of the economic literature on CPR has tried to unfold the structural links between some parameters of the game characterizing players' interactions and the collective efficiency, with regard to both the provision for the CPR and the investment to exploit it.

The structure of the Prisoners' Dilemma is such that the only Nash equilibrium of the game corresponds to the situation where players make collectively inefficient choices. Both Ostrom et al. (1994) and Baland and Platteau (1996) propose to replace the initial Prisoners' Dilemma setting in the more general framework of games between two players in their strategic forms. Ostrom et al. (1994) present the other possible types of games depending on the respective values of the payoff coefficients (such as chicken game or assurance game). They show that these other types of games can provide a relevant analysis in certain CPR situations. In these games, there is no dominant strategy: players can benefit from coordination. Therefore, the interest of a corpus of management rules (including controls and mechanisms for sanctions) may rely on transforming a Prisoners' Dilemma into a game, of which the Pareto optimum is one of the Nash equilibria and therefore selfenforcing (Ostrom, 1990). In the same way, Heckathorn (1993) establishes a typology of two-player games when these players have to contribute to the provision of a public good.

\subsection{Repetition During Time}

If the initial game has a Prisoners' Dilemma structure, and if this game is repeated a finite and known number of times, then there is a unique Nash equilibrium, which is for players to act in a collectively inefficient way. By contrast, a high number of collectively efficient strategies can be Nash equilibria, if (i) the game is repeated an infinite number of times; (ii) the game is repeated a finite but unknown number of times; or (iii) the players are forced to act with incomplete information about how rivals will behave. This can take place with two or more players (Seabright, 1993). Such a result is known as the folk theorem, which states that 'almost any outcome that on average yields at least the mutual defection payoff to each player can be sustained as a Nash equilibrium' (Baland and Platteau, 1996). Generally speaking, these strategies are of the 'tit for tat' structure, defined as an initial collectively efficient choice associated with a temporary or definitive punishment in front of a partner who would have cheated. These strategies are history-dependent and are based on the presence or absence of trust, i.e. the expectation that one player has of others' behaviours (Seabright, 1993).

\subsection{Trying to Formalize the Existence of Norms}

Many simulations based on experimental economics show that agents' behaviours cannot be completely explained by the rational choice of the best strategy in a non-cooperative setting. First, the efficiency of informal discussions is not taken into account, because the game models do not incorporate the 'cheap talks', which allow agents to learn about each other. Second, the models do not integrate the existence of moral behaviours. Many experiments show indeed that agents do not follow a purely self-interested strategy, but rather strike a balance between self and group interests (Cardenas et al., 2000). For instance, the set-up of sanction mechanisms is a public good, and therefore, it is subjected to the problem of free riding. The theory predicts hence an under-provision 
of this 'good'. Nevertheless, in many experiments, the players are ready to pay for the implementation costs of a sanction system (Ostrom et al., 1994).

Finally, in an experimental economics simulation, Cardenas and Ostrom (2001) show that agents cooperate better if they can discuss face-to-face between each step of the game, than if an external regulation system randomly audits players' actions. Face-to-face discussions allow for a better efficiency of resource management even if they do not lead to any verifiable commitment. These discussions are more efficient when all users take part in them (Schmitt et al., 2000). The preceding theories fail to explain such a result.

Hence, there are situations where players show a form of morality that transforms the initial gains into subjective ones. Two main questions can therefore be raised. What kind of statute moral norms should be given in game models? What are the situations where players display a moral behaviour and what are the ones where they do not? Two sketches of answers have been proposed recently: first, the inclusion of moral norms in players' utility functions, and second, a classification of information categories mobilized by agents.

\subsubsection{Inclusion of Moral Norms in Players' Utility Functions}

Recently, several articles have proposed to modify players' utility functions in a traditional CPR game, in order to take into account moral norms ${ }^{4}$. For instance, Falk et al. (2002) define a player's utility function by subtracting from the player's material payoff utility losses coming from disadvantageous inequities (differences of profit with players having a better payoff) as well as coming from advantageous inequities. Evolutionary game theory has also recently brought some new insights. In the setting of evolutionary game theory, each agent uses a given strategy, for example a moral sense that induces the player to systematically cooperate. The population of the game is composed of types of agents using different strategies. These agents meet on a random basis and then play a given game. At the end of each interaction period, the types of agents that obtained the best profits will see their overall share in the population augmented. When such an approach is applied to biology, the usual interpretation is that the groups that get the best gains will reproduce better than others. When applied to economics, a simple interpretation is that, at the end of each period, a certain number of agents will change their minds and hence their strategies, and this will occur proportionally to the relative gains among the different strategies. Hence, according to this approach, agents are not able to estimate the efficiency of all possible strategies, but they can see the strategies used by others, assess their results and they can change their minds. Ultimately, it is an interesting way to take into account a bounded rationality. Next, an evolutionary stable strategy is defined as a strategy that, when played by the whole population, is able to resist the invasion of agents using a different strategy (Weibull, 1995). In such a setting, a Nash equilibrium in mixed strategy corresponds simply to an equilibrium in population shares between two groups playing different strategies.

Sugden (1986, cited by Baland and Platteau, 1996) shows that, in a situation based on a Prisoners' Dilemma game, the tit-for-tat strategy is evolutionary stable, meaning that it is able to impose itself on ever-cooperating agents or always-cheating ones. Bester and Gu" th (1998) define an 'indirect'

\footnotetext{
${ }^{4}$ The idea of using morality to solve a problem of the Prisoners' Dilemma type was mentioned by Hardin in 1968 but he rejected it, estimating that a moral norm that would decrease one agent's appropriation of the resource would be self-eliminating.
} 
evolutionary theory by proposing to modify the gains of the game (for instance, the Prisoners' Dilemma structure) depending on the moral cost or benefit for an agent to cooperate or cheat. Bester and Gu" th in their study examine the interaction between two players. Each of them chooses a certain amount of effort, with a mutual externality that can be either positive or negative. Altruism is represented by the fact that agents can take into account a share of the partner's profit in their utility function. The model shows that, given a positive externality, a certain strictly positive level of altruism is the only evolutionary stable strategy, whereas if the externality proves to be negative, only selfishness will be evolutionary stable. Nevertheless, in case of a positive externality, if the population is initially composed of selfish and altruistic people and if agents know only the proportion of both types, then the altruistic type will decline. This result can explain the importance of cheap talks before each agent takes her own decision, in the field and during experimental economics simulations.

Hence, according to Cardenas and Ostrom (2001), there are three main elements which can explain collectively efficient choices: (i) the structure of the game (e.g. a repeated game); (ii) a strictly positive probability to meet people from the same type; and (iii) the existence of institutions that give a nonmonetary bonus for cooperating (prestige, reputation, etc.).

This theoretical approach can explain the interest of setting up institutions for cooperation, because they create social norms, gather information on the agents' types and design systems for rewards and punishments. Nevertheless, while this approach provides some elements explaining how an agent can freely choose a collectively efficient action, it does not deal with agents' abilities to craft management rules.

\subsubsection{The Use of Norms Depends on the Context of the Game}

Cardenas and Ostrom (2001) propose to distribute the different layers of information used by an agent in the following manner: The static game layer stands for the knowledge of the matrix of possible actions and gains. The dynamic game layer corresponds to the information gathered during previous games. The group layer gathers the information on other players and especially their propensity to cooperate. Finally, the individual layer stands for the agent's own morality, for instance, the importance given to cooperating.

Depending on the structure of the game and on the available layers, a player will put forward a given layer of information to take a decision, because gathering information on other players (i.e. the dynamic and group layers) may be costly. Hence, in the case of a perfect market, only the first layer will be taken into account. By contrast, when the transaction costs of establishing contracts to secure the choice of collectively efficient actions are important, the agent may mobilize other layers of information. The agent will accept to take time to have informal discussions with other players in order to estimate whether they have moral norms that induce them to preferably cooperate, even if these discussions do not lead to any verifiable commitment afterwards. Depending on the different layers of information gathered, the player will modify the initial objective gains into subjective ones, which for instance, may transform an initial Prisoners' Dilemma structure into an assurance game or a chicken game. 


\subsection{The Joint Study of Problems of Under-provision and Over-investment}

Finally, several articles combine the two issues of provision and appropriation in a CPR setting.

\subsubsection{Combining Incentives for Under-effort and Over-effort}

In some Japanese fisheries, an income-sharing rule creates an incitation for sharing the technical knowledge and also limits the problem of over-investment (Gaspart and Seki, 2000). The overinvestment inherent in any fishing activity in a CPR setting is indeed compensated by the incentive to behave as a free rider, regarding the collective production. In the same manner, Schott (2001) searches for the optimal size for fisher grouping so that the sum of these two opposite effects leads to an optimal fishing effort. According to Schott, a main advantage of such an approach is that a redefinition of property rights is not needed.

In fact, if players maximize their profits, then only the tax they have to pay matters. Therefore, the previous system combining income-sharing and freeriding is equivalent to a Pigouvian tax, which means that a low tax level will lead to an over-investment problem whereas a too strong tax pressure will lead to an under-investment outcome. A certain amount of taxation (i.e. a certain amount of profit redistribution) hence permits to reach the collective optimum. The model with profit sharing differs from the Pigouvian tax only in terms of the value earned from taxes being redistributed among users. Such redistribution will ease the implementation of the management system.

\subsubsection{The Necessary Congruency between Provision and Allocation Rules}

In his study of 48 Mexican irrigated schemes, Dayton-Johnson (2000a) shows, as Ostrom (1992), the necessary congruency between water allocation rules and rules sharing the costs of maintenance. Similarly, De Janvry et al. (1998) propose a model where agents can choose both the levels of provision and of appropriation. In this model, agents can also coordinate themselves in order to limit the overinvestment on appropriation, but the implementation of control mechanisms is costly. They show that a better enforcement of the appropriation problem will lead to an increased provision for the common good. Therefore, coordination on appropriation can be expected to be higher in resources where provision is needed (e.g. grazing where users can individually encroach on the common pasture to farm privately) than for resource where there is no need for provision (e.g. fishery).

\section{The Negotiation on the Rules to Manage CPRs}

This section deals with the ability of agents to design their own rules, in order to shift from an unmanaged situation to a managed one. Many scholars have analysed the set up of a managed CPR (for instance, Baland and Platteau, 1996; Ostrom, 1999; McCay, 2002). However, the use of formal decision-making models, especially game theory models, has been far less developed than in the previous case of a given management rule. Before presenting a short review of these models, it is first shown that it may be possible to use, at least partially, the former results obtained in a noncooperative setting to get insights in the way management rules are chosen. 


\subsection{Potential Use of the Former Results with a Non-cooperative Setting}

It is now assumed that agents may gather themselves in order to set up rules. Their discussion may lead to rules that will bind users' choices and organize them in order to achieve a Pareto-optimal situation. The choice of the rule will depend on the structure of the negotiation process and agents' respective decision-making powers.

Let us assume a situation where (i) it is technically possible to set up rules that decrease or eliminate the free rider problem, by limiting the extent of actions that a player can perform and (ii) players can communicate. In such a situation, every cooperative game can be described as a non-cooperative game. In other words, whatever the structure of the game, each player has a choice among different actions (for instance, advocating different rules or siding with other players). Each action will reward individual player's outcomes, which in turn will depend on the behaviours of other agents. This associated non-cooperative game is called hereafter the metagame.

The payoffs of the metagame matrix will incorporate the transaction costs as well as the potential results of coalitions. Therefore, given this matrix, the preceding results on the impact of the structure of the game (size, heterogeneity, etc.) can be used. For instance, Baland and Platteau (1998) propose a qualitative discussion on the possibility of setting up different rules, given the non-cooperative results attached to each of them.

In addition, the general matrix of payment for the metagame can be of a Prisoners' Dilemma type. For instance, suppose that the payoff matrix of the initial game is the left table on Figure 3. Let us assume that the transaction costs to set up a rule (which guarantees that each player will play the collectively efficient action) amount to two units. This cost can be shared among players if both of them decide to participate in the set up of the rule. The right table on Figure 3 presents the payoff matrix of the corresponding metagame, which indeed shows a Prisoners' Dilemma structure. Without communication, no agent will set up the new rule alone. Nevertheless, if the two players can communicate and make their choices nonrevocable (assumption of a cooperative game), they can agree to set up the new rule together. Because the rule ensures that, afterwards, players make collectively efficient choices, the Tragedy of the Commons is prevented.

However, compared to the non-cooperative setting, there is the additional complexity of representing the interactions among players able to participate in coalitions. The different solutions proposed by game theorists (Shapley value, Nash bargaining and core of the game) do not necessarily lead to the same results, and some research still needs to be done to understand their respective meanings (Bergin and Duggan, 1999; see also Abbink et al., 2003; for the relatively theoretical literature on the links between cooperative and non-cooperative approaches). 

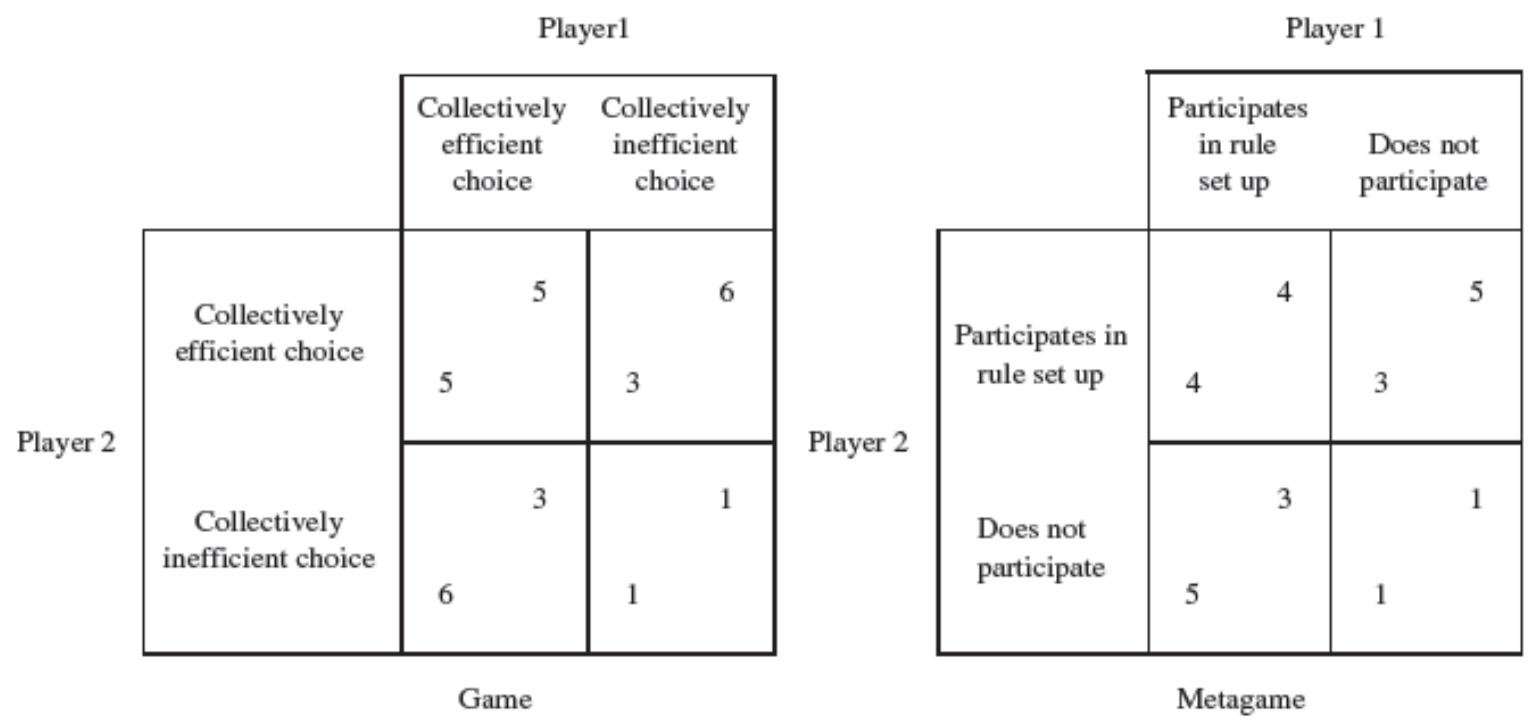

Figure 3. Example of a game and an associated metagame.

\subsection{Existing Results with a Cooperative Setting}

One possible way to analyse a process of negotiation consists in using cooperative game theory. With regard to environmental issues, the main topic in which such theory was used is the negotiation on global commons, an example being the atmosphere or the fish stocks in international waters. In these cases, there is no supra-national state, which would be able to dictate the relevant solution. By contrast, the use of cooperative games for the study of local CPR is limited for the moment.

In a very generic way, Ostrom (1999) argues that there will be a change towards a managed CPR if there is a minimal coalition of users for whom the benefits of shifting from an unmanaged to a managed CPR outweigh the costs of designing new rules, monitoring and sanctioning. In the McCarthy et al. (2001) model, the community can choose the costs they are ready to invest in monitoring the exploitation of the resource and, thus, a level of appropriation between the optimal one and the one corresponding to the Nash equilibrium of over-exploitation. The monitoring costs chosen will increase with agents' incentives to act in a collectively inefficient way. This model can account for the partial levels of cooperation observed in the field.

Gardner et al. (2000) study the use of a proportional limitation in order to decrease the overexploitation of a CPR. They determine the level of reduction that will be voted by the majority rule. Walker et al. (2000) set up a simulation of experimental economics where players withdraw individually from the CPR. Starting from an initial non-regulated situation, players can propose a resource allocation, then the different propositions are voted. The use of such rules can considerably increase the global efficiency, and in the given setting the unanimity rule is more efficient that the majority rule. 
Finally, Funaki and Yamato (1999) look at the capacity for identical players to avoid the Tragedy of the Commons. They show that the existence of a core is linked to the hypothesis each coalition makes on the possibility of coordination of other players outside the coalition. On the one hand, if each coalition makes optimistic forecasts, i.e. thinks that outsiders will coordinate themselves (and hence reduce their total exploitation of the resource), then the core may be empty. On the other hand, if each coalition makes pessimistic assumptions, i.e. thinks that the outsiders' actions will lead to the worst result, then the core always exists. In fact, pessimistic and optimistic situations are related to two important concepts of cooperative game theory (theories alpha and beta, Shubik (1982). The result proposed by Funaki and Yamato is very simple, nevertheless, it is a very promising one regarding the use of cooperative game models to analyse CPR. The impact of heterogeneity on the results of a negotiation is by nature different from the impact of heterogeneity on the collective efficiency for a given allocation rule. Indeed, the increase of the provision for the resource is always beneficial for all agents, as well as the decrease of the amount of appropriation. By contrast, regarding the creation of regulation rules, it is generally necessary to assess the shift from an initial unmanaged situation to a managed one. The shift from one situation to the other can lead to a decrease in outcomes for a certain subset of the agents' group. This may happen when an agent benefiting from the resource better than others loses during the shift towards a managed situation, for example one based on uniform quotas (Baland and Platteau, 1998). This situation is more likely to happen when the group is heterogeneous. The possibility to organize some monetary transfers can theoretically solve this problem. Nevertheless, in many cases, these transfers will not be used because of a lack of definition of rights or for cultural reasons. In order to conclude, the managed situation can profit or on the contrary be unfavourable to rich agents, compared to the unmanaged situation. In this case, relations have to be more untangled before results can be proposed. From the case study side, Dayton-Johnson's (2000a) study of Mexican irrigation schemes shows that wealth inequality increases the probability of observing proportional allocation.

In the case of heterogeneity in social position and in the kind of interest for the resource, several authors agree on the idea that differences in social origins and in types of use of the resource will impede the building of a common knowledge of the resource. This will in turn complicate the set up of structures of regulation (Baland and Platteau, 1996; Varughese and Ostrom, 2001; Bardhan and Dayton-Johnson, 2002).

In conclusion, three main reasons can explain the existence of unmanaged situations: (i) the high costs of the possible monitoring rules; (ii) the high transaction costs of changing the rulel; and (iii) the fact that some users profit from this unmanaged situation and manage to block any institutional change.

\section{The Contribution of Economic Analysis to the Debate Over CPR}

This last part of the review provides a very brief assessment of the theory's ability to fit with experimental data, and the impact of this research on policies actually adopted to manage CPR. 


\subsection{A Restricted Ability of Game Theoretic Models to Represent Observed}

Behaviours

At this juncture, a general conclusion can be proposed. The Nash equilibrium provides an accurate description of collective interactions both in real case studies and in experimental economics simulations, when agents cannot communicate and more generally, when a social capital is difficult to create (Ostrom, 2000a). Besides, Ito et al. (1995) point out that, in some cases, an observed total investment greater than the Nash equilibrium can be explained by the assumption that agents do not maximize their own profit but rather try to maximize the difference between their revenue and the ones of others. Nevertheless, case studies and experimental economics simulations show that the present theory fails to account for the following two points.

First, while the Nash equilibrium provides an accurate description of the strategies taken as a whole, agents do not play individually the Nash equilibrium strategies. Using an experimental economics simulation, Keser and Gardner (1999) show that students' choices lead on the whole to the computed Nash equilibrium but that less than $5 \%$ of these students really use the Nash equilibrium strategy. Moreover, the observed behaviour is not coherent with the backward induction process that is used in the analysis of finitely repeated games. Finally, the theory does not take into account the trials and errors process used by individuals. Therefore, there is a need to take better into account a bounded rationality.

Second, the theory has not dealt much with agents' ability to change the management rules. From a theoretical point of view, the approach proposed by Funaki and Yamato (1999) is very promising but it is still far from being able to illustrate real case studies.

\subsection{No Blanket Solution Regarding the Best Property Regime to Avoid the Tragedy of the Commons}

Broadly speaking, two approaches were put forward after Hardin's article (1968), in order to avoid the Tragedy of the Commons (Berkes et al., 1989). The first approach consists in defining individual transferable property rights. Indeed, any Pareto optimum can be obtained when the market on these rights is perfect. Nevertheless, in a CPR setting, such a condition is almost never met. Moreover, when markets on these rights are incomplete, negotiations can also result in a Pareto optimum, as proposed by the so-called Coase theorem (Coase, 1960). Nevertheless, the transaction costs must be null and with a number of players greater or equal to three, the negotiation space may not have a core (Baland and Platteau, 1996). The second approach consists in nationalizing the resource. This solution has been widely used in many countries in Africa and Asia in the years following the accession to independence. However, two problems appeared then, the first being a lack of means to control the access on resource, and secondly, a problem of information asymmetry between the State and the users. In most of the cases, nationalization has led to an actual situation of free access.

A large amount of literature shows that, in some cases, a management based on a group property can be more efficient than either the nationalization or a market based on transferable individual rights (see, for instance, the numerous studies conducted by the International Association for the Study of Common Property). There is therefore no general solution for the free rider problem that could come from a given property regime (Dietz et al., 2002). More research is still needed to link 
property regimes and the parameters of the game. For instance, Tietenberg (2002) analyses the use of tradable permits to solve the CPR problem and finds that they are of interest in situations where externalities not taken into account by the permits are small, and where users get high benefits from the resource (for instance the resource being the air that can receive pollution from industries). Rose (2002) shows that group property outperforms private property when the resource is complex (there are interactions among various aspects of the resource) and varies over time.

\section{Perspectives for Future Research}

Given the results of the analyses presented above, three main directions for theoretical research can be proposed. ${ }^{5}$

- It will be necessary to base CPR analyses on models using a more bounded rationality (Keser and Gardner, 1999; Ostrom, 2000a). These models will have to incorporate norms, defined as an opinion shared among a group that some rules should be followed and that it is necessary to punish the fraudsters. For instance, one of the major norms that will have to be taken into account is the tit-for-tat strategy. As for the definition of a social capital, there is nevertheless the risk of signing a blank cheque.

- Many models currently used are based on a two-player structure, especially those dealing with heterogeneity. These models over-estimate the impact of each user's action on the collective resource. It seems more realistic to design models with a large number of players, even if these models are simplified by considering that, for calculating the Nash equilibria, each player does not take into account the impact of her own effort on the global effort made on the resource. The results for two and for a larger number of players may be qualitatively very different.

- On the whole, the analyses made focused mainly on the application of rules and not much on their selection. It is necessary to build negotiation theories applied to the CPR context. The approach proposed by Funaki and Yamato (1999) on such issue is a promising one.

Three other perspectives for more applied future research seem also of importance:

- A link is to be made between the large literature on environmental economics tools (quotas, taxes, permits, etc.) and the economic analysis of CPR. The latter has concentrated on the regime of property rights and on the influence of the different parameters of the system, but few works compare different classical economic tools in the context of a CPR (see Rose, 2002; Tietenberg, 2002).

- Game theoretic models have shown that many parameters of the game could play a role in departing from the initial Prisoners' Dilemma outcome. The spectre of an unavoidable Tragedy of the Commons now seems far away. Moreover, most of the studies, which tried to link observed behaviour and theory, are based on experimental economics simulations. For these two reasons, it may be of interest to build models on a case-by-case basis, from detailed case studies, using more realistic production functions and game structures (e.g. Faysse, 2003).

\footnotetext{
${ }^{5}$ See also Stern et al. (2002) for some proposals concerning directions for future research.
} 
- There is a need to quantify in a simple way the benefits of several rules for the different groups of users within a community as well as the transaction costs, without necessarily delving into complex cooperative game theory models. 'The crucial factor is not whether all attributes are favourable, but the relative size of the expected benefits and costs they generate as perceived by the participants' (Ostrom, 1999). Analyses of costs and benefits such as proposed by Ostrom (1999) can be quantified.

\section{Conclusion}

The review described how the problem of the commons is described in New Institutional Economics terms, and what are the recent answers economists have provided, with a specific focus on game theory models. The use of game theory model is now part of the standard course on CPR. However, these games are still very schematic, are disconnected from real field studies and focus almost only on agents' behaviours within a given management situation.

As Cardenas (2003) experiences and others have shown, the social characteristics of players are of key importance in a situation where players have initially the same payoffs structure. While it is important to understand in a more humble way the place that game theory models have in a general analysis, there is definitely a need for more research on the negotiation of rules, using game theory and transaction cost measures on real case studies.

\section{Acknowledgement}

The author thanks Jacques Weber for some seminal ideas.

\section{References}

Abbink, K., Darziv, R., Gilula, Z., Goren, H., Irlenbusch, B., Keren, A., Rockebach, B., Sadrieh, A., Selten, R. and Zamir, S. (2003). The fisherman's problem: Exploring the tension between cooperative and non-cooperative concepts in a simple game. Journal of Economic Psychology 24: 425-445.

Baland, J. and Platteau, J. P. (1996). Halting Degradation of Natural Resources, is there a Role for Rural Communities? Oxford: FAO and Clarendon Press.

Baland, J. and Platteau, J. P. (1997). Wealth inequality and efficiency in the commons. Part I: The unregulated case. Oxford Economic Papers 49: 451-482.

Baland, J. and Platteau, J. P. (1998). Wealth inequality and efficiency in the commons. Part II: The regulated case. Oxford Economic Papers 50: 1-22.

Baland, J. and Platteau, J. P. (1999). The ambiguous impact of inequality on local resource management. World Development 27: 773-788. 
Baland, J. and Platteau, J. P. (2002). Collective action on the commons: The role of inequality. Workshop on "Inequality, Collective Action and Environmental Sustainability", Santa Fe Institute, New Mexico, November 2002.

Bardhan, P. (2000). Irrigation and cooperation: An empirical analysis of cooperation on irrigation in South India. Economic Development and Cultural Change 48: 847-865.

Bardhan, P. and Dayton-Johnson, J. (2002). Unequal irrigators: Heterogeneity and commons management in large-scale multivariate research. In E. Ostrom, T. Dietz, N. Dolsak, P. C. Stern, S. Stonich and E. U. Weber (eds), The Drama of the Commons, Division of Behavioral and Social Sciences and Education. Washington, DC: National Academic Press.

Bardhan, P., Ghatak, M. and Karainov, A. (2002). Inequality and collective action. Workshop on "Inequality, Collective Action and Environmental Sustainability", Santa Fe Institute, New Mexico, November 2002.

Bergin, J. and Duggan, J. (1999). An implementation-theoretic approach to non-cooperative foundations. Journal of Economic Theory 86: 50-76.

Bergstrom, T., Blume, L. and Varian, H. (1986). On the private provision of public goods. Journal of Public Economics 29: 25-49.

Berkes, F., Feeny, D., McCay, B. and Acheson, J. (1989). The benefits of the commons. Nature 340: 91-93.

Bester, H. and Güth, W. (1998). Is altruism evolutionarily stable? Journal of Economic Behavior \& Organization 34: 193-209.

Cardenas, J.-C. (2003). Real wealth and experimental cooperation: Evidence from the fields. Journal of Development Economics 70: 263-289.

Cardenas, J.-C. and Ostrom, E. (2001). What do people bring into the game? How norms help overcome the tragedy of the commons. In: 4th Toulouse Conference on Environment and Resource Economics 'Property Rights, Institutions and Management of Environmental and Natural Resources', Toulouse (France), May 3-4, 2001.

Cardenas, J.-C., Stranlund, J. and Willis, C. (2000). Local environmental control and institutional crowding-out. World Development 28: 1719-1733.

Coase, R. (1960). The problem of social cost. Journal of Law and Economics 3(1): 1-44.

Dayton-Johnson, J. (2000a). Choosing rules to govern the commons: A model with evidence from Mexico. Journal of Economic Behavior \& Organization 42: 19-41.

Dayton-Johnson, J. (2000b). Determinants of collective actions on the local commons: A model with evidence from Mexico. Journal of Development Economics 62: 81-208.

Dayton-Johnson, J. and Bardhan, P. (2002). Inequality and conservation on the local commons: A theoretical exercise. Economic Journal 112: 577-602. 
De Janvry, A., McCarthy, N. and Sadoulet, E. (1998). Endogenous provisions and appropriation in the commons. American Journal of Agricultural Economics 80: 658-664.

Dietz, T., Dolsak, N., Ostrom, E. and Stern, P. C. (2002). The drama of the commons. In E. Ostrom, T. Dietz, N. Dolsak, P. C. Stern, S. Stonich and E. U. Weber (eds), The Drama of the Commons, Division of Behavioral and Social Sciences and Education. Washington, DC: National Academic Press.

Falk, A., Fehr, E. and Fischbacher, U. (2002). Appropriating the commons: A theoretical explanation. In E. Ostrom, T. Dietz, N. Dolsak, P. C. Stern, S. Stonich and E. U. Weber (eds), The Drama of the Commons, Division of Behavioral and Social Sciences and Education. Washington, DC: National Academic Press.

Farrell, J. and Scotchmer, S. (1988). Partnerships. Quarterly Journal of Economics 103: 279-297. Faysse, N. (2003). Allocating irrigation water: The impact of strategic interactions on the efficiency of rules. European Review of Agricultural Economics 30(3): 305-332.

Funaki, Y. and Yamato, T. (1999). The core of an economy with a common pool resource: A partition function form approach. International Journal of Game Theory 28: 157-171.

Gardner, R., Herr, A., Ostrom, E. and Walker, J. (2000). The power and limitations of proportional cutbacks in CPR. Journal of Development Economics 62: 515-533.

Gaspart, F. and Seki, E. (2000). Sharing, heterogeneity and status consideration: Incentive theory and empirical evidences. In: Eighth Biennial Conference of the International Association for the Study of Common Property, Bloomington, IN, USA, June 2000.

Hardin, G. (1968). The tragedy of the commons. Science 162: 1243-1248.

Hardin, G. (1998). Extension of "the tragedy of the commons". Science 280: 682-683.

Harsanyi, J. C. (1966). A general theory of rational behavior in game situations. Econometrica 34(3): 613-634.

Heckathorn, D. (1993). Collective action and group heterogeneity: Voluntary provision versus selective incentive. American Sociological Review 58: 329-350.

Holmstrom, B. (1982). Moral hazard in teams. BELL Journal of Economics 13: 324-340.

Ito, M., Saijo, T. and Une, M. (1995). The tragedy of the commons revisited. Identifying behavioral principles. Journal of Economic Behavior \& Organization 28: 311-335.

Keser, C. and Gardner, R. (1999). Strategic behavior of experienced subjects in a common pool resource game. International Journal of Game Theory 28: 241-252.

Kherallah, M. and Kirsten, J. F. (2002). The new institutional economics: Applications for agricultural policy research in developing countries. Agrekon 41(2): 111-133.

McCarthy, N., Sadoulet, E. and De Janvry, A. (2001). Common pool resource appropriation under costly cooperation. Journal of EnvironmentalEconomics andManagement 42: 297-309. 
McCay, B. J. (2002). Emergence of institutions for the commons: Contexts, situations, and events. In E. Ostrom, T. Dietz, N. Dolsak, P. C. Stern, S. Stonich and E. U. Weber (eds), The Drama of the Commons, Division of Behavioral and Social Sciences and Education. Washington, DC: National Academic Press.

Olson, M. (1965). The Logic of Collective Action: Public Goods and the Theory of Groups. MA: Harvard University Press.

Ostrom, E. (1990). Governing the Commons: The Evolution of Institutions for Collective Actions. Cambridge, UK: Cambridge University Press.

Ostrom, E. (1992). Crafting Institutions for Self-Governing Irrigation Systems. Oakland, CA: Institute for Contemporary Studies Press.

Ostrom, E. (1999). Self-governance and Forest Resources. CIFOR Occasional Paper 20, Bogor, Indonesia.

Ostrom, E. (2000a). A behavioral approach to the rational choice theory of collective action. In M. McGinnis (ed.), Polycentric Games and Institutions. Ann Arbor: Univesity of Michigan Press.

Ostrom, E. (2000b). Collective action and the evolution of social norms. Journal of Economic Perspectives 14: 137-158.

Ostrom, E., Burger, J., Field, C. B., Norgaard, R. B. and Policansky, D. (1999). Revisiting the commons: Local lessons, global challenges. Science 284: 278-282.

Ostrom, E., Gardner, R. and Walker, J. (1994). Rules, Games and Common Pool Resources. Michigan: University of Michigan Press.

Rose, C. M. (2002). Common property, regulatory property and environmental protection: Comparing community-based management to tradable environmental allowances. In E. Ostrom, T. Dietz, N. Dolsak, P. C. Stern, S. Stonich and E. U. Weber (eds), The Drama of the Commons, Division of Behavioral and Social Sciences and Education. Washington, DC: National Academic Press.

Schmidt, C. (2001). La théorie des jeux. Essai d'interprétation. Paris, France: Presses Universitaires de France.

Schmitt, P., Swope, K. and Walker, J. (2000). Collective action with incomplete commitment: Experimental evidence. Southern Economic Journal 66: 829-854.

Schott, S. (2001). A partnership solution to the tragedy of the commons. In: 4th Toulouse Conference on Environment and Resource Economics 'Property Rights, Institutions and Management of Environmental and Natural Resources' Toulouse (France), May 3-4, 2001.

Seabright, P. (1993). Managing local commons: Theoretical issues in incentive design. Journal of Economic Perspectives 7(4): 113-134.

Shubik, M. (1982). Game Theory in the Social Sciences. MA: MIT Press. 
Stern, P. C., Dietz, T., Dolsak, N., Ostrom, E. and Stonich, S. (2002). Knowledge and questions after 15 years of research. In E. Ostrom, T. Dietz, N. Dolsak, P. C. Stern, S. Stonich and E. U. Weber (eds), The Drama of the Commons, Division of Behavioral and Social Sciences and Education. Washington, DC: National Academic Press.

Tietenberg, T. (2002). The tradable permits approach to protecting the commons: What have we learned? In E. Ostrom, T. Dietz, N. Dolsak, P. C. Stern, S. Stonich and E. U. Weber (eds), The Drama of the Commons, Division of Behavioral and Social Sciences and Education. Washington, DC: National Academic Press.

Varughese, G. and Ostrom, E. (2001). The contested role of heterogeneity in collective action: Some evidence from community forestry in Nepal. World Development 29: 747-765.

Walker, J., Gardner, R., Herr, A. and Ostrom, E. (2000). Collective choice in the Commons: experimental results on proposed allocation rules and votes. Economic Journal 110: 212-234.

Weibull, J. (1995). Evolutionary Game Theory. MA: MIT Press.

Wittfogel, K. A. (1957). Oriental Despotism: A Comparative Study of Total Power. New Haven: Yale University Press. 